\title{
Meniscal and ligament modifications in spontaneous and post-traumatic mouse models of osteoarthritis
}

Lorenzo Ramos-Mucci', Behzad Javaheri', Rob van 't Hof', George Bou-Gharios' ${ }^{1}$, Andrew A. Pitsillides', Eithne Comerford ${ }^{1,3}$ and Blandine Poulet ${ }^{1^{*}}$ (i)

\begin{abstract}
Background: Osteoarthritis $(\mathrm{OA})$ is a whole joint disease that affects all joint tissues, with changes in the articular cartilage (AC), subchondral bone and synovium. Pathologies in menisci and ligaments, however, are rarely analysed, although both are known to play vital roles in the mechanical stability of the joint. The aim of our study was to describe the pathological changes in menisci and ligament during disease development in murine spontaneous and post-traumatic surgically induced $O A$ and to quantify tissue mineralisation in the joint space using microcomputed tomography $(\mu \mathrm{CT})$ imaging during OA progression.

Methods: Knees of Str/ort mice (spontaneous OA model; 26-40 weeks) and C57CBA F1 mice following destabilisation of medial meniscus (DMM) surgery (post-traumatic OA model; 8 weeks after DMM), were used to assess histological meniscal and ligament pathologies. Joint space mineralised tissue volume was quantified by $\mu \mathrm{CT}$.

Results: Meniscal pathological changes in Str/ort mouse knees were associated with articular cartilage lesion severity. These meniscal changes included ossification, hyperplasia, cell hypertrophy, collagen type II deposition and Sox9 expression in the fibrous region near the attachment to the knee joint capsule. Anterior cruciate ligaments exhibited extracellular matrix changes and chondrogenesis particularly at the tibial attachment site, and ossification was seen in collateral ligaments. Similar changes were confirmed in the post-traumatic DMM model. $\mu \mathrm{CT}$ analysis showed increased joint space mineralised tissue volume with OA progression in both the post-traumatic and spontaneous OA models.

Conclusions: Modifications in meniscal and ligament mineralisation and chondrogenesis are seen with overt AC degeneration in murine OA. Although the aetiology and the consequences of such changes remain unknown, they will influence stability and load transmission of the joint and may therefore contribute to OA progression. In addition, these changes may have important roles in movement restriction and pain, which represent major human clinical symptoms of OA. Description of such soft tissue changes, in addition to AC degradation, should be an important aspect of future studies in mouse models in order to furnish a more complete understanding of OA pathogenesis.
\end{abstract}

Keywords: Osteoarthritis, Mouse models, Anterior cruciate ligament, Meniscus

\footnotetext{
* Correspondence: b.poulet@liverpool.ac.uk

${ }^{1}$ Institute of Lifecourse and Medical Sciences, University of Liverpool, 6 West Derby street, L7 8TX Liverpool, UK

Full list of author information is available at the end of the article
}

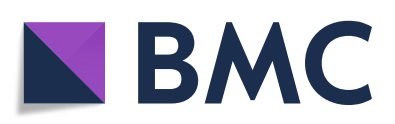

(- The Author(s). 2020 Open Access This article is licensed under a Creative Commons Attribution 4.0 International License, which permits use, sharing, adaptation, distribution and reproduction in any medium or format, as long as you give appropriate credit to the original author(s) and the source, provide a link to the Creative Commons licence, and indicate if changes were made. The images or other third party material in this article are included in the article's Creative Commons licence, unless indicated otherwise in a credit line to the material. If material is not included in the article's Creative Commons licence and your intended use is not permitted by statutory regulation or exceeds the permitted use, you will need to obtain permission directly from the copyright holder. To view a copy of this licence, visit http://creativecommons.org/licenses/by/4.0/. The Creative Commons Public Domain Dedication waiver (http://creativecommons.org/publicdomain/zero/1.0/) applies to the data made available in this article, unless otherwise stated in a credit line to the data. 


\section{Introduction}

Osteoarthritis (OA) is a degenerative joint disease that leads to joint pain and restricted movement. Loss of articular cartilage $(\mathrm{AC})$ characterises $\mathrm{OA}$ and is a hallmark of disease progression, but surrounding joint tissues including subchondral bone [1], synovium [2], menisci and ligaments are also affected [3]. Stability of the joint can influence OA progression and can be targeted to induce OA through surgical meniscectomy and ligament transection [4-6]. Despite the integral role of menisci and ligaments in maintaining normal joint function, few studies have examined their changing pathology during the development of disease in mouse models of OA [712]. Herein, we illustrate structural changes in the knee menisci and ligaments during OA development in two mouse models, including spontaneous (Str/ort mouse) and post-traumatic (destabilisation of medial meniscus, DMM) OA models.

Though composition of menisci differs between mice and humans, menisci likely play similar stabilising roles in both species. Human knee menisci are fibrocartilaginous and contribute to load transmission and joint stability [13]. Unlike humans, mouse menisci are ossified and can be subdivided into three parts: a central bone core with marrow cavities, hyaline cartilage at the surface opposite tibial and femoral articulating surfaces and an outer region of fibrocartilage tissue near the joint capsule [14]. In both species, the meniscus is attached to the femur and tibia by various ligaments [5].

Ligaments also stabilise knee joints by restricting excessive tibial movement relative to the femur in both animals and humans [15]. The cruciate ligaments prevent excessive antero-posterior and rotational movements, and the collateral ligaments restrict medio-lateral displacement [15]. Mouse ligaments have a similar structure and function to human ligaments [16]. The importance of ligament and meniscal stabilising functions is perhaps best exemplified by the induction of OA after ligament transection and meniscal injuries in a range of species, including both mouse $[4,5]$ and human [17-19]. Several findings also suggest meniscal [19] or ligament damage $[20,21]$ occurs in early stages of spontaneous OA. Despite these indications, meniscal and ligament pathology are not well understood.

Mouse models of OA are important tools to define mechanisms of disease and to determine targets to slow disease progression [22]. The main murine models for OA include spontaneous and mechanical induction models [23]. Many laboratory mouse strains develop OA with age [24]. The Str/ort mouse is known to exhibit early-onset OA (visible OA seen by 18 weeks of age) with high incidence and severity and reproduces many human OA features, such as proteoglycan loss, cartilage fibrillation, active degradation of cartilage extracellular matrix, osteophyte formation and subchondral bone thickening [8, 25-29]. These hallmarks are also well described in post-traumatic models of OA such as the DMM model, induced by surgical transection of the meniscotibial ligament [5, 30, 31]. Pathological changes in meniscus and ligaments are poorly described in these models of OA. Thus, the aim of this study was to explore the meniscal and ligament pathological changes during OA development in spontaneous and posttraumatic $\mathrm{OA}$ in mice, including tissue mineralisation in the joint space using micro-computed tomography $(\mu \mathrm{CT})$ imaging and specific cellular and matrix markers of chondrogenesis using immunohistochemistry.

\section{Materials and methods}

\section{Animals}

Male CBA (Charles River, UK), Str/ort (in-house, Royal Veterinary College, London, UK) and C57-CBA F1 mice (Charles River, UK) were kept in polypropylene cages, subjected to $12 \mathrm{~h}$ light/dark cycles, at $21 \pm 2{ }^{\circ} \mathrm{C}$ and fed standard RM1 maintenance diet ad libitum (No.1; Special Diet Services, Witham, UK). All procedures complied with Animals (Scientific Procedures) Act 1986 and local ethics committee.

Male Str/ort mice aged $26(n=7)$ and 40 weeks $(n=$ 14) were used; these age groups allowed the full extent of OA development encompassing a range of severity grades of disease (from grades 1 to 6 ; incidence of mice with each OA grade: grade $1, n=1$; grade $2, n=2$; grade $3, n=8$; grade $4, n=5$; grade $5, n=4$; grade $6, n=1$ ). Thus, changes in the meniscal and ligament tissues were assessed based on the grade of AC lesion severity as a measure of OA severity using the internationally recognised OARSI grading system for AC loss [32]. For the $\mu C T$ analysis, a second group of Str/ort mice were used $(n=8)$ all at the same age in order to minimise the effect of age on meniscal size. These mice were used at 37 weeks of age, which showed variability in OA severity grades ranging from grades 3 to 6 [33]. For toluidine blue and immunohistochemical staining, Str/ort samples were compared to aged-matched CBA controls $(n=6$ per group).

\section{DMM}

Surgical destabilisation of the medial meniscus was performed on the right knee joint in $n=13$ male C57CBA F1 mice at 10 weeks old as described before [34]. Briefly, anaesthesia was induced by injection of $10 \mu \mathrm{l} / \mathrm{g}$ of Hypnorm $^{\oplus} /$ Hypnovel $^{\odot}$ (at a ratio of 1:1-4 parts water), the right knee joint was accessed via a medial incision. The meniscotibial ligament was transected, resulting in the release of the medial meniscus from its tibial attachment. After transection, the skin was sutured and mice were immediately transferred to a heated post-operative 
recovery room. All animals received buprenorphine $\mathrm{HCl}$ (Vetergesic; Alstoe Animal Health, York, UK) subcutaneously post-surgery and monitored daily to ensure good health. Incidence of OA severity in the $n=13$ mice ranged from grade 2 to 6 , as follow: grade $2, n=2$; grade $3, n=5$; grade $4, n=2$; grade $5, n=2$; grade $6, n=2$. For $\mu \mathrm{CT}$ analysis, toluidine blue and immunohistochemical staining samples were compared to contralateral controls.

\section{$\mu \mathrm{CT}$}

Cadaveric knee joints were scanned with a $5-\mu \mathrm{m}$ isotropic voxel size $(50 \mathrm{kV}, 200 \mu \mathrm{A}$, respectively, $0.5 \mathrm{~mm}$ aluminium filter; $0.6^{\circ}$ rotation angle, no frame averaging) using a Skyscan $1172 \mu \mathrm{CT}$ scanner (Skyscan, Belgium). Hand-drawn regions of interests of the whole menisci (lateral and medial) and other mineralised tissues (which include mineralisation of ligaments) that were not part of the tibial or femoral bones were analysed using $3 \mathrm{D}$ algorithms in CTAn (Skyscan, Belgium) to provide the mineralised tissue volume (measured as Bone Volume on CTAn). Statistical analysis of mineralised volume comparing the different groups within each OA model was performed using Student's $t$ test for the DMM, and ANOVA with Bonferroni post hoc test for the Str/ort mouse model. Three-dimensional models of the menisci were created using CTVox from the region of interest selected for mineralised tissue volume analysis (Skyscan, Belgium).

\section{Histology}

Animals were killed by cervical dislocation and knee joints prepared for $\mu \mathrm{CT}$ imaging and/or histology. Briefly, skin and muscles were removed, the joints fixed in neutral buffered formalin, stored in 70\% ethanol and scanned as described above. For histology, joints were decalcified (ImmunocalTM, Quarttet, Berlin, Germany), dehydrated and processed for wax embedding. Serial coronal $6-\mu \mathrm{m}$-thick sections were cut across the entire joint and a quarter of the entire set from regular intervals across the joint stained with toluidine blue $(0.1 \%$ in $0.1 \mathrm{M}$ solution of acetate buffer, $\mathrm{pH} 5.6$ ) and counterstained with $0.2 \%$ fast green for $5 \mathrm{~s}$. Toluidine blue was used for histological examination to assess pathophysiological changes in menisci and ligaments.

\section{Immunohistochemistry}

Immunohistochemistry was performed to localise expression of collagen type II (Col2) (Thermo, Mouse MC) and Sox9 (Abcam, Rabbit PC). Histology slides were dewaxed and rehydrated. For Col2, antigen retrieval was applied with pepsin $(3 \mathrm{mg} / \mathrm{mL}$ in $0.02 \mathrm{M} \mathrm{HCl})$ for $45 \mathrm{~min}$ at $37^{\circ} \mathrm{C}$. Slides were then washed and blocked for endogenous peroxidase with $0.3 \%$ hydrogen peroxide for
$15 \mathrm{~min}$ at $37^{\circ} \mathrm{C}$ (Sigma). Next, slides were blocked for endogenous Avidin/Biotin binding with an Aviding/Biotin Blocking Kit (Vector Labs, SP2001). Non-specific binding sites were blocked for $1 \mathrm{~h}$ (Col2: MoM Kit, Vector Labs, BMK-2202; Sox9: 10\% v/v goat serum). Primary antibodies were incubated overnight at $4{ }^{\circ} \mathrm{C}$ and included Col2 (1/100, Thermo) and Sox9 (1/1000, EMD Millipore). Negative controls included a mouse IgG $(2 \mu \mathrm{g} / \mathrm{mL}$, Sigma, for Col2) or rabbit IgG $(1 \mu \mathrm{g} / \mathrm{mL}$, Vector Labs, for SOX9; Supplementary Fig. 1). Following washing, biotinylated secondary antibody (Vector Labs) was applied for $1 \mathrm{~h}$ and then Vectastain (Vector Labs) for $30 \mathrm{~min}$. Stains were developed with DAB (Vector Labs), dehydrated and mounted with DPX (Sigma).

\section{Results}

\section{Osteoarthritic meniscal changes in Str/ort mice include} chondrogenesis and ossification of the outer region of the meniscus

To investigate the pathological changes in meniscus during osteoarthritis in mice, we used histological staining in healthy CBA mouse knee joint compared to osteoarthritic Str/ort mouse joints. Toluidine blue staining of the healthy CBA mouse knee joints $(n=8)$ delineated the expected bone and hyaline cartilage surface components of the meniscus (Fig. 1a, CBA). Additionally, Collagen type II (Col2; collagen specific to cartilage tissues) immunolabelling was present only in the hyaline cartilage surfaces of the meniscus, facing the articular femur and tibial cartilage. The chondrogenic marker Sox 9 was sparsely expressed in the hyaline cartilage cells but not in the fibrous region.

Knee joints from a group of male adult Str/ort mice (aged 26 and 40 weeks, $n=21$ ) were graded for AC degradation using the OARSI grading system showing a range of severities (grades 1-6). The range of meniscal pathology occurred mainly in the medial compartment and included osteophyte formation at the meniscal tip, chondrogenesis and ossification in the fibrous region, as well as hypertrophy at the attachment site and erosion. The severity of pathological changes in the medial meniscus of Str/ort mice increased with AC degradation severity scored according to the OARSI grading system (Fig. 1b-d). The first notable change in early stages of OA (grade 2) was an increase in the outer fibrous region of the meniscus, which further increased with disease progression. In OA grade 4 and higher, this expanding fibrous region showed evidence of hyperplasia, chondrogenesis and formation of bone marrow cavities. The changes included increased toluidine blue staining and the appearance of rounded chondrocyte-like cells particularly in the region attaching to the joint capsule. Immunohistochemistry showed Col2 deposition in the fibrous region, particularly in areas surrounding bone formation and in the outer areas near the capsular 

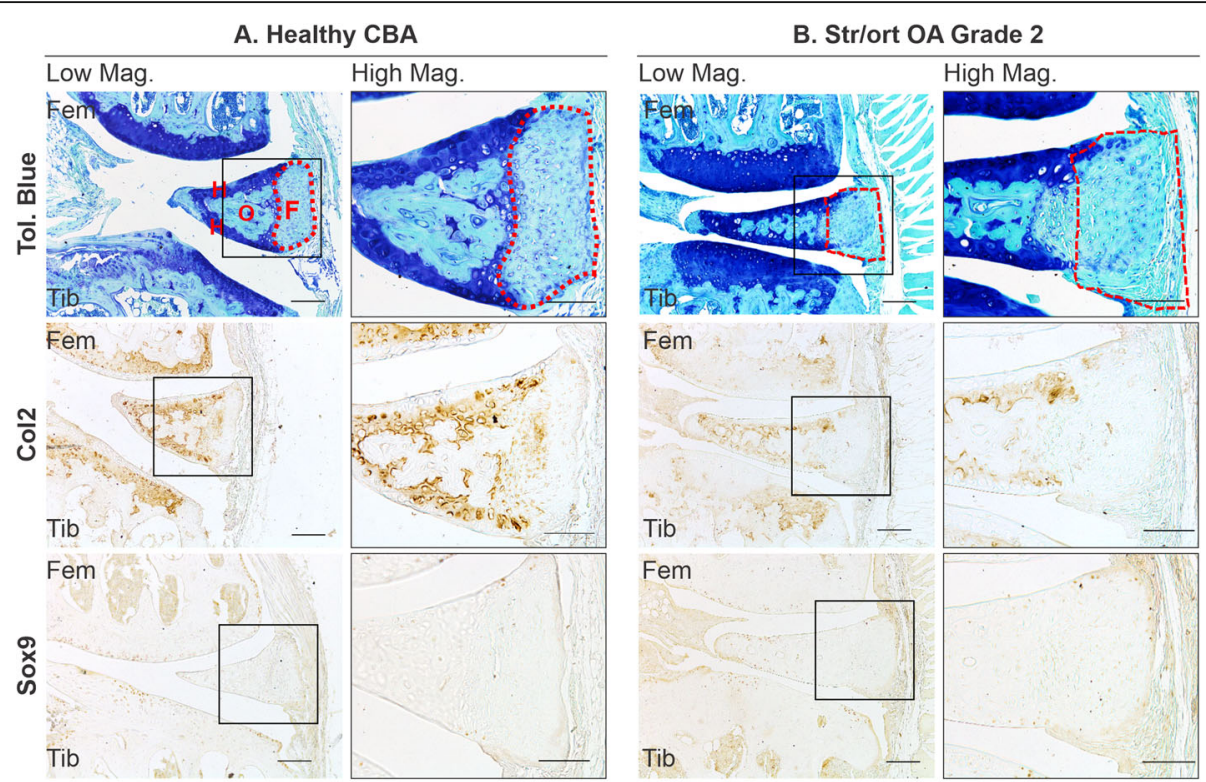

C. Str/ort OA Grade 4
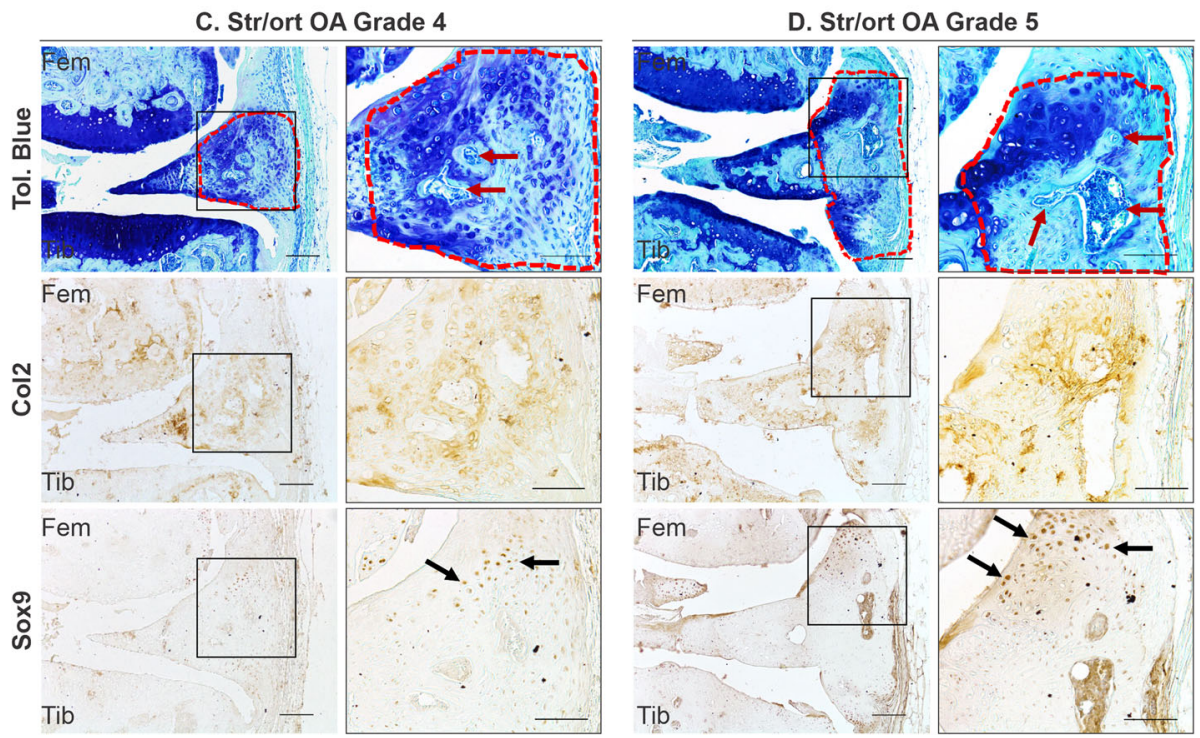

Fig. 1 Representative images of meniscal pathology during spontaneous osteoarthritis development in Str/ort mice. a Toluidine blue, Collagen type II (Col2) and Sox9 immunolabelling in healthy CBA mouse meniscus, which can be divided into distinct regions: hyaline cartilage (H) surrounds an ossified region $(\mathrm{O})$ and an outer fibrous (F) region. b-d Representative images from diseased menisci from Str/ort mouse knee joints with OA grades of 2 (mild), 4 (moderate) and 5 (severe). Toluidine blue staining showed a range of meniscal pathologies associated with OA development including an increase in the fibrous region (delineated by red lines), proteoglycan deposition and bone formation (red arrows). Col2- and sox9-positive cells (black arrows) were seen in the fibrous region of the meniscus with disease showed. Low mag = low magnification, scale bar $=100 \mu \mathrm{m}$; High mag = high magnification, scale bar $=50 \mu \mathrm{m}$. For orientation: femur at top of picture, tibia bottom

attachment site. Similarly, Sox9-positive cells were prominent in the edges of the fibrous compartment of the meniscus.

\section{Cruciate and collateral ligaments developed areas of chondrogenesis during osteoarthritis in Str/ort mouse knees}

Ligaments, the stabilisers of the knee joint, are comprised of aligned spindle-shaped cells and dense collagenous fibres which stain only weakly with toluidine blue in healthy joints (Fig. 2a). The anterior cruciate ligament (ACL) in Str/ort joints with AC lesions of grade 2 or greater contained ACLs with clear chondrogenic changes including positive toluidine blue staining, thickening of fibres and rounded hypertrophic cells evident at the tibial insertion (Fig. 2). In more severe OA cases, positive toluidine blue staining expanded through the entire ACL and insertion site and showed signs of 


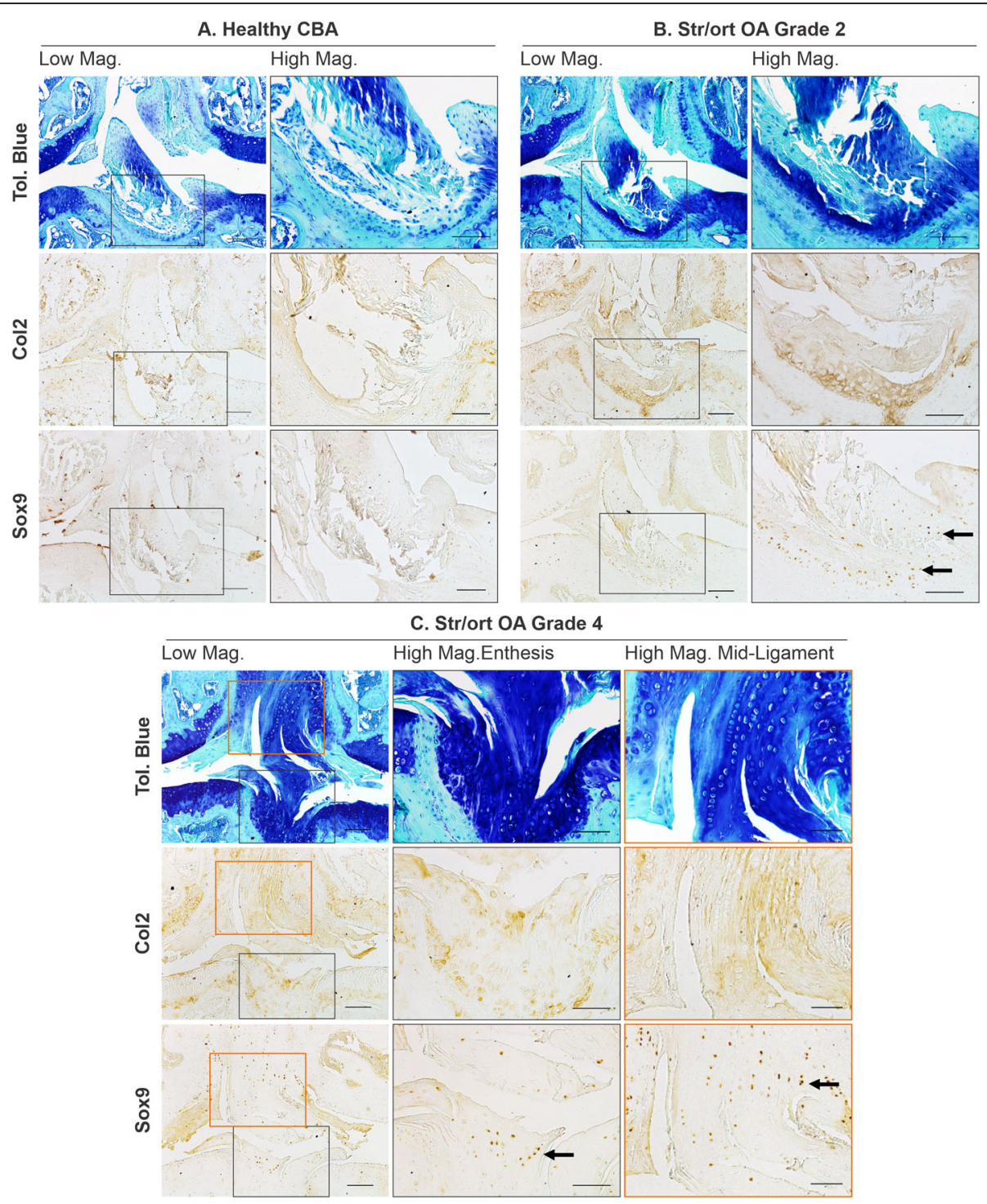

Fig. 2 Representative images of cruciate ligament changes with OA development in Str/ort mice. a Toluidine blue, Collagen type II (Col2) and Sox9 immunolabelling in healthy CBA mouse cruciate ligaments, with high magnification of insertion site into the tibia. $\mathbf{b}$, c Cruciate ligaments from Str/ort mouse knee joints with OA grades of 2 (mild) and 5 (severe). Toluidine blue staining showed increased staining at the insertion site (high mag for panels $\mathbf{b}$ and $\mathbf{c}$ ) and within the ligament body (high mag for panel $\mathbf{c}$ ), with hypertrophy of local cells. Col2 deposition and sox-9 positive cells were also increased, especially in severe diseased joints. Low mag = low magnification, scale bar = $100 \mu \mathrm{m} ;$ High mag = high magnification, scale bar $=50 \mu \mathrm{m}$. For orientation: femur at top of picture, tibia bottom

misalignment and degeneration, with columns of hypertrophic cells. Immunohistochemistry confirmed changes in the ACL extracellular matrix and cellular markers in the Str/ort mouse knee joint, with Col2 deposition in the ACL tibial insertion sites (Fig. 2). Sox9 expression was seen within cells of the ligament insertion site and extended to the cells within the ligaments (Fig. 2). Col2 deposition and Sox9 expression in the ligament or insertion site were not observed in the healthy CBA ligaments (Fig. 2).

Collateral ligaments link the femur and tibia on the lateral/medial sides of the joints. Similarly to ACL, cells in collateral ligaments in healthy CBA joints are spindleshaped and form small columns along the ligament fibres, which are devoid of Col2 deposition (Fig. 3a). Cells within the body of the ligament have very mild Sox 9 expression. In Str/ort mice, collateral ligaments showed signs of overt thickening, increased toluidine blue staining, cell hypertrophy and areas of bone formation (Fig. 3). These features are consistently accompanied by positive local labelling for Col2 deposition and Sox9 expression. In very severely osteoarthritic joints, marked structural changes with significant bone nodule formation can be seen; in these joints, the attachment site is also modified 


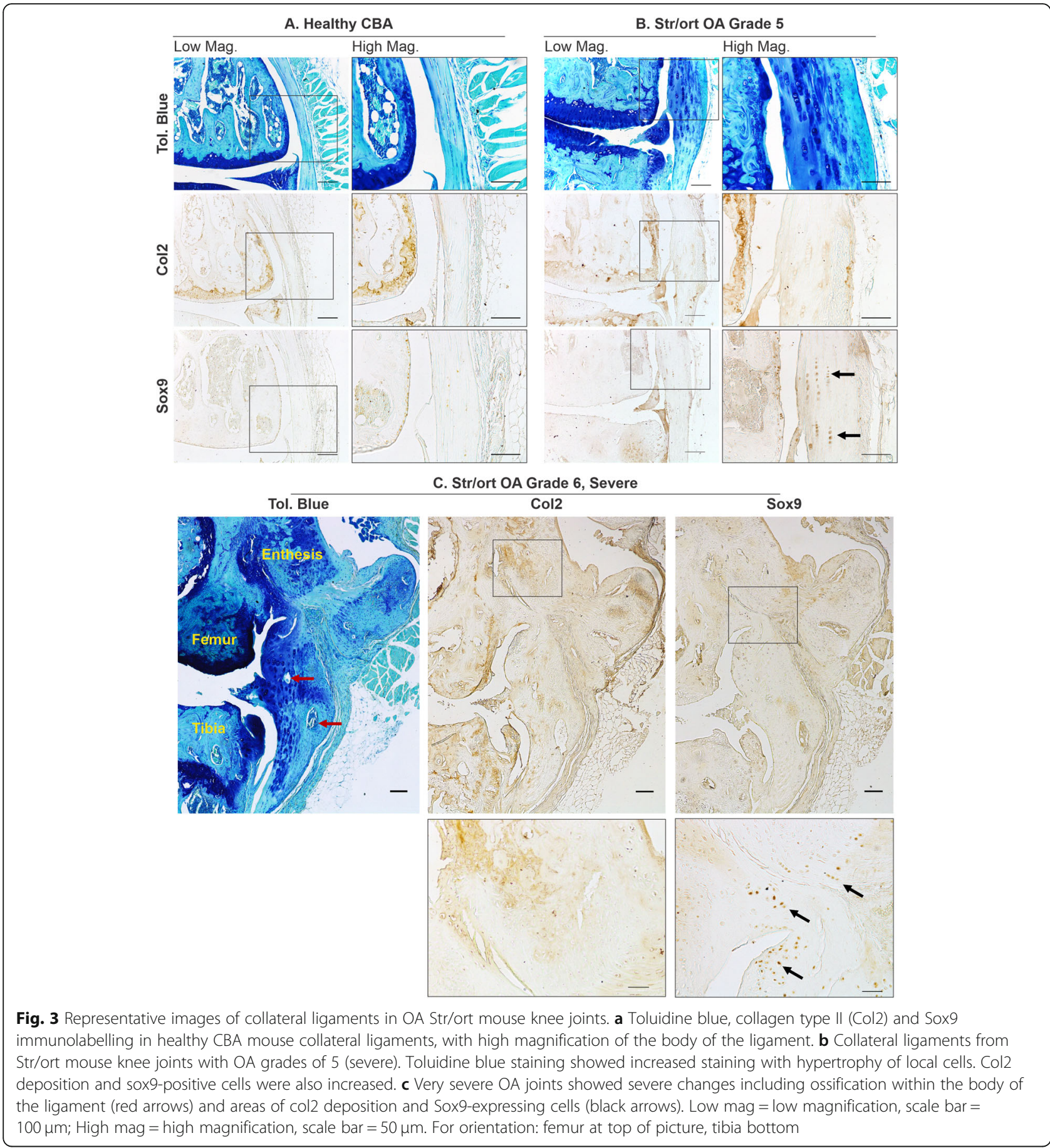

with bone formation extending into the ligament (Fig. 3c).

Histological analysis of a post-traumatic OA mouse model reveals chondrogenic and hyperplasic changes in the menisci and ligaments

The post-traumatic model of osteoarthritis (DMM) $(n=$ 13) lead to moderate OA development 8 weeks postsurgery, with an average AC degradation OARSI grade of $3.4 \pm 0.3$, primarily in the medial compartment. Similar meniscal changes to Str/ort mouse knee joints were seen in this port-traumatic model of OA (see Table 1). The medial meniscus showed hyperplasia of meniscal attachments seen as a significant thickening, and chondrogenesis followed by ossification in the outer fibrous compartment, including blood vessel invasion and the formation of marrow spaces (Fig. 4). Toluidine blue staining was also noted in the areas surrounding bone 
Table 1 Summary of meniscal and ligament changes in two murine models of knee osteoarthritis. Maximum OA grades reported for Str/ort mice based on the OARSI grading system, to group these changes according to the severity of OA in a model that shows variability

\begin{tabular}{lll}
\hline & Spontaneous OA (Str/ort mouse) & Surgical model (DMM) \\
\hline OA grade & 26 weeks, 2.57 \pm 1.1 & $3.61 \pm 0.3$ \\
Meniscus & 40 weeks, 3.62 \pm 1.5 & \\
Meniscal osteophyte formation at tip & Grade 3-5 & Yes \\
Outer part chondrogenesis & Grade 3-4 & Yes \\
Outer part ossification & Grade 3-5 & Yes \\
Hypertophy of attachment & Grade 4-6 & Yes \\
Erosion & Grade 6 & Yes (grade 6) \\
Ligaments (cruciates, collaterals) & & Yes \\
Strong ECM staining & Grade 3-6 & Yes \\
Cell hypertrophy & Grade 3-6 & Yes \\
Cell clustering & Grade 4-6 & Yes \\
Loss of alignment & Grade 4-6 & Yes \\
Ossification & Grade 4-6 & \\
\hline
\end{tabular}

formation and near the capsular attachment along with evidence of cell hypertrophy. The tibial insertion site of the ACL displayed increased proteoglycan staining with toluidine blue and evidence of cell hypertrophy (Fig. 4). The ACL also showed signs of disorganisation, including thickening and misalignment of the fibres.

\section{Quantification of joint space mineralisation by $\mu \mathrm{CT}$ analysis reveals significant increases in mineralisation volumes in osteoarthritic mouse knees}

Mineralised tissues can be visualised in 3-dimensions (3D) and quantified using X-ray based $\mu \mathrm{CT}$ imaging techniques. Using this technique, we aimed to quantify the changes described above to the soft tissues, including ligament and meniscal cartilage/bone formation. To achieve this, we used knee joints $(n=8)$ from Str/ort mice with a range of cartilage lesion severities (from grade 3 to 6), and from C57CBA F1 mice at 8 weeks following DMM surgery $(n=7)$ and their contralateral healthy joints, for $\mu \mathrm{CT}$ analysis of the joint space. These analyses showed that Str/ort mouse knee joints developed increased mineralised tissue volume within the joint space with increasing severity of cartilage lesion grades in Str/ort mice (Fig. 5a). Similarly, an increase in

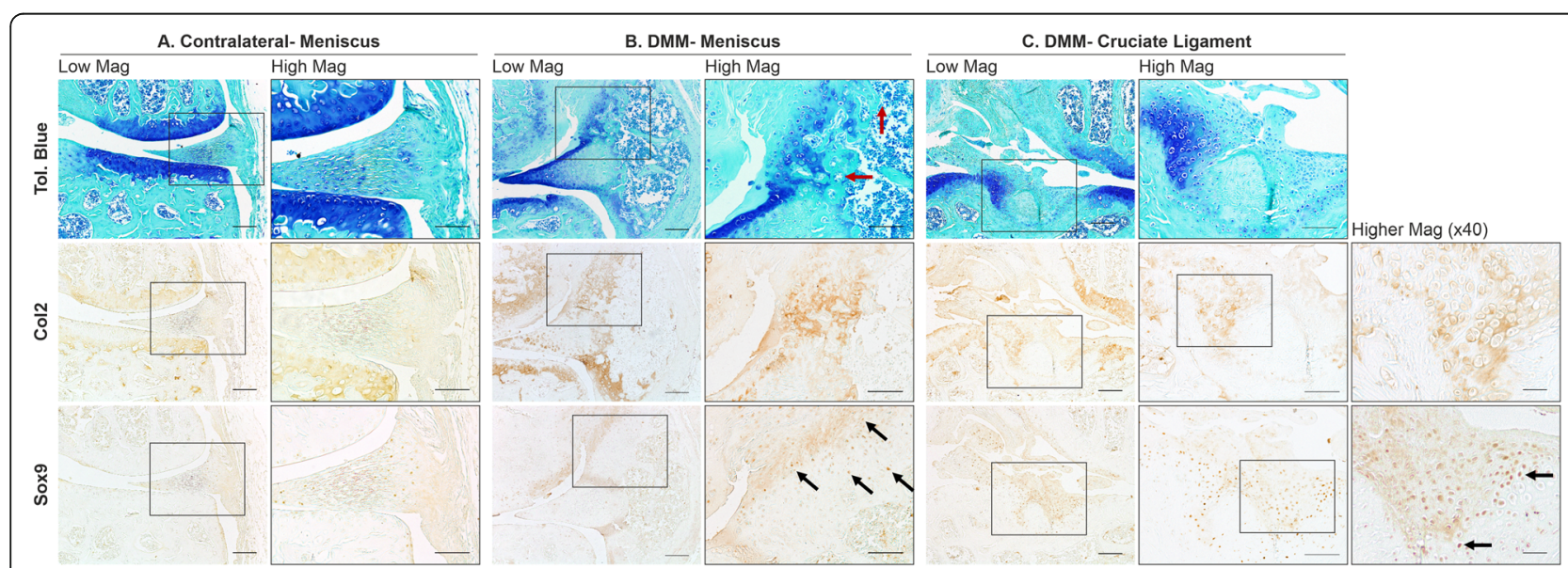

Fig. 4 Representative images of meniscus and ligament modifications during post-traumatic OA in DMM joints. a Staining of the contralateral control meniscus. $\mathbf{b}$ Toluidine blue staining showed meniscal changes in the DMM mice associated with OA development, including bone formation in the fibrous meniscal attachment site, proteoglycan and bone deposition (red arrow). Col2 deposition was also seen at the sites of high toluidine Blue staining with Sox9-expressing cells (black arrows). c Cruciate ligament insertion site in DMM joints showed areas of strong toluidine blue staining, concomitant with col2 deposition and Sox9 expression. Low mag = low magnification, scale bar = $100 \mu \mathrm{m}$; High mag = high magnification, scale bar $=50 \mu \mathrm{m}$ 
mineralised tissue volume was also found in response to DMM surgery compared to the untreated contralateral leg (Fig. 5c).

Representative 3D images of this mineralised tissue however showed differing patterns of pathological mineralisation between these models. The Str/ort mice joints showed early changes in the medial compartment (grade 4 ), which is also the primary location of cartilage lesions, but developed to more widespread abnormal mineralisation in distinct nodules around both menisci (medial and lateral) in severe OA (grade 6; Fig. 5b). In contrast, the DMM model, which induces OA mainly in the medial compartment, showed increased mineralisation primarily around the medial meniscus primarily compared to contralateral untreated control limbs (Fig. 5d).

Overall, $\mu \mathrm{CT}$ analysis of the mouse knee showed quantifiable mineralisation changes in the joint space with OA progression.

\section{Discussion}

This study describes the pathological changes to the menisci and ligaments during osteoarthritis development in distinct mouse models of OA, including spontaneous Str/ort mouse and surgical post-traumatic DMM models. It is important to assess both types of models as they represent distinct OA subtypes that may develop via different cellular mechanisms [35], and their analyses will allow us to define common potential treatment options regardless of the initiating factor or those that are more specific. We found abnormal patterns of chondrogenesis, ossification, cell hypertrophy, meniscal erosion and loss of fibre alignment in ligaments in both models. Pathological changes in both meniscal and ligamentous tissues indicated endochondral ossification markers included collagen type II matrix formation and Sox9 expression. Moreover, we described the use of $\mu \mathrm{CT}$ analysis to quantify these changes in soft tissue mineralisation/ossification with OA development. These data suggest a common pathway for OA changes in the menisci and ligaments in mice in both spontaneous and post-traumatic disease.

Similar studies have reported changes in non-articular cartilage tissues during OA development in mice. Some of the meniscal changes reported herein have been briefly reported in Str/ort mice [7-9] and more recently in the DMM mouse model [36], with a general histological analysis but no description of the ACL. The description of knee osteoarthritis in Str/ort mice by Walton and others $[8,9]$ includes reports of heterotopic calcification. In particular, they describe an increased ossification centre in the medial meniscus [8] and a positive association between medial collateral ligament calcification and OA development [9]. These findings agree with our histological data of meniscal ectopic mineralisation and ossified nodules in the collateral ligaments in Str/ort mice. Anderson-MacKenzie et al. showed that Str/ort mice ACLs have increased MMP-2, high collagen remodelling and decreased mechanical
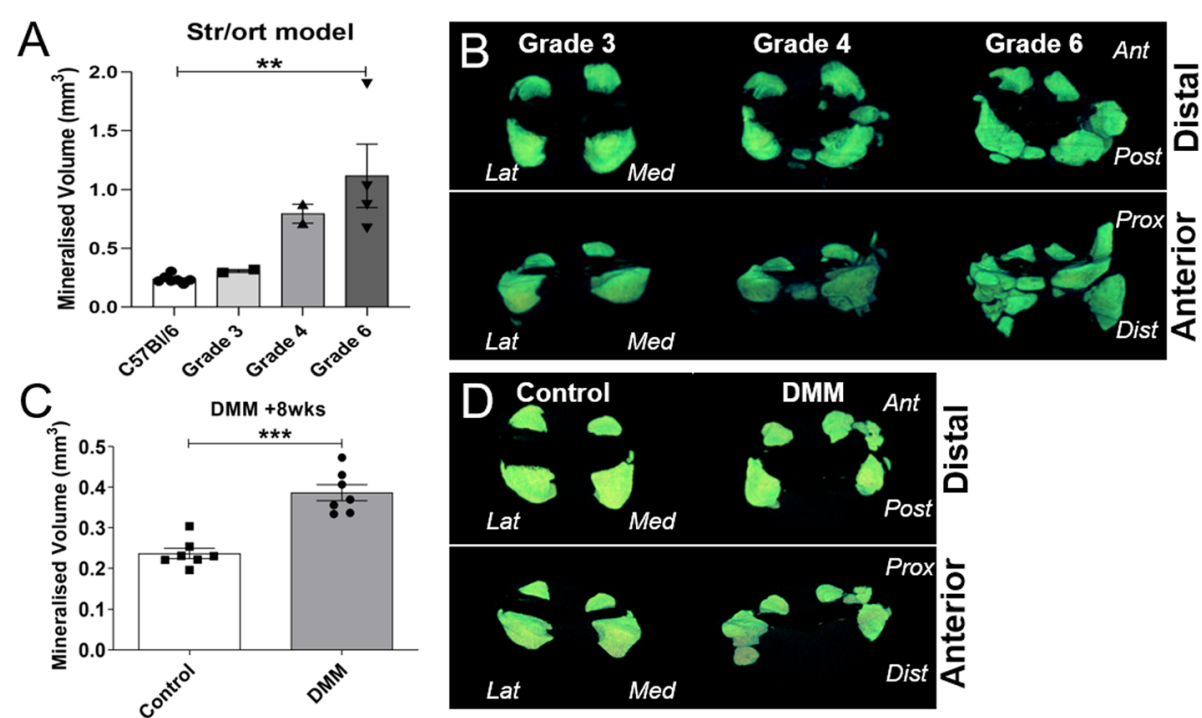

Fig. 5 HCT-based quantification and 3D images of joint space mineralisation with OA progression in Str/ort mice and in response to posttraumatic DMM surgery. a Analysis showed volume of mineralised tissue in the joint space increased with disease severity in Str/ort mice $(n=8)$ and healthy $\mathrm{C} 57 \mathrm{BI} / 6$ mice $(n=7)$. $\mathbf{b}$ This increase was also visualised in 3D as enlargement of the meniscus and ectopic mineralisation nodules of different sizes (distal and anterior views). c Similar increases in mineralised tissue volume were noted 8 weeks following DMM surgery compared to the contralateral control knee $(n=7)$, $\mathbf{d}$ with mineral nodules primarily in the medial side of the joint. (Lat $=$ Lateral; Med = Medial; Ant = Anterior; Post $=$ Posterior; Prox $=$ Proximal; Dist $=$ Distal). ${ }^{* * *}$ for $p>0.001$, based on $t$ test between control and DMM. Data presented as mean $\pm \mathrm{SEM}$ 
strength compared to healthy CBA joints in 27-week-old Str/ort mice, at which time histological OA is well underway [20]. Meanwhile, Kwok et al. showed murine DMM menisci with severe fibrillations, erosion and calcifications [36]. This also matches our histological results and is further strengthened by our $\mu \mathrm{CT}$ mineralisation measurements and our immunohistochemistry, which provides quantification of these changes and insight into the matrix and cellular changes involved.

Col2 and Sox 9 markers are typically cartilage-specific markers crucial for endochondral ossification processes. With the exception of ligament enthesis insertion sites [37], positive expression these cartilage markers are not expected in normal ligaments. Healthy menisci express these cartilage markers on the cartilage surface of the main body of the meniscus [11, 14], but not in the outer compartment of the meniscus, where most of the OA changes we describe occur. Similarly to our findings, Col2 and Sox9 have been associated with OA development in human ACLs [38] and confirmed the chondrogenic nature of our observed increased toluidine blue staining in the meniscus and ligament in murine OA.

In humans, meniscal pathologies have been associated with ageing and OA. Indeed, the meniscus commonly develops lesions in OA patients with no previous history of injury [39]. Although meniscal ossicles are rare in humans and arise mainly from mechanical trauma [40], calcification is more common and found mainly in OA patients [41, 42]. In addition, aged and OA menisci showed changes in cellularity (with both areas of hyperand hypocellularity), cell clustering and phenotype changes from fibroblast-like cells to round chondrocytelike cells [42], similar to our findings in mouse OA. Similarities in meniscal pathologies between human and mouse OA support a favourable translatability between the species, despite clear meniscal structural differences (i.e. ossified meniscus in mouse). Pathological meniscal ossification has also been described in other animal models of OA. In the guinea pig model of spontaneous OA, for example, the extent of meniscal ossification has been found to correlate significantly with disease severity [43]. In the same model, treatment with an antimineralisation agent blocked meniscal calcification and cartilage damage [44]. Meniscal ossification is also an important feature in osteoarthritic dogs and pigs [45, 46]. In pigs, meniscal ossification was associated with abduction of the hindlegs, stiff locomotion and reduced weight gain, indicative of a painful condition [45]. On the other hand, in a rat model of DMM, histological scoring found no differences in meniscal ossification between sham and DMM groups [47]. Incidence of increased meniscal ossification in a majority OA species confirms the need to determine the mechanisms involved that could have broad implications for controlling OA development.

The pathological chondrogenesis of ligaments described in mouse knee joints in this study also shows many similarities to human joints $[48,49]$. It has been found that human cruciate ligaments from OA patients show important chondroid and cartilage metaplasia, which involve a change in ligament cell phenotype to a more chondrocyte-like round cell morphologies $[38,50]$. This included positive Col2 and collagen type X labelling in areas of chondroid metaplasia along with Sox9 and RUNX2 expression in chondrocyte-like cells [38]. The mechanisms of pathological chondrogenesis and ossification in these ligaments remain, however, largely undefined.

In addition to a link with OA development [51-55], factors linked to ligament ossification include Indian hedgehog, Wnt and inflammatory cytokine signalling $[48,49,56]$. It was also reported that COL6A1 and RUNX2 may be common susceptibility genes in ligament ossification in the spine $[57,58]$ and both of these genes have also been linked to OA [59, 60]. Transforming growth factor $\beta$ (TGF $\beta$ ) and bone morphogenetic proteins (BMPs) are known regulators of ossification and fibrosis as well as being involved in OA development and have also been associated with ligament ossification, including recombinant BMP2 in rat spines [61] and abnormal BMP signalling in human spines [62]. Recently, epidermal growth factor signalling was linked to OA development, comprising of ectopic chondro-osseous pathologies in the ligament and meniscus [10]. Mechanical trauma or disturbances are possible factors that contribute to these pathological ossifications, with evidence that ossification of ligaments is increased in response to mechanical loading [63-66]. Our study describes changes in a model of spontaneous OA (Str/ort); although the aetiology of OA development in this model is largely unknown, it does not preclude the possible changes in the joint mechanical environment during disease development in this model that could promote these ligament pathologies. In fact, similarities in the meniscal and ligament pathogenesis between spontaneous and post-traumatic models of OA suggest a common pathway for these events. Future work in mouse models will define important pathways involved in these pathologies to target OA development.

It is still uncertain, however, whether such meniscal and ligament changes contribute to OA progression. They might influence joint stability and load transmission, therefore accelerating $\mathrm{OA}$ and restricting the range of movement. Furthermore, damage in ligaments and menisci in human elderly patients has been linked with knee pain [67], so the associated ossification, with neoangiogenesis and innervation, may increase joint pain 
[68] possibly leading to gait modifications. Further studies in murine models of OA might help decipher the aetiology of pain and restricted movement-the main clinical manifestations in human OA, as well as providing a better understanding of $\mathrm{OA}$ as a whole joint organ disease.

Most meniscal and ligament pathologies in OA are generally based on histological description, which are qualitative and at best semi-quantitative based on a scoring system of specific histological hallmarks [32, 69]. In this study, we have used $\mu \mathrm{CT}$ imaging to better quantify changes in joint space tissues, including ligaments and meniscus. We found that there was a clear increase in mineralised tissue volume in the joint space and OA progression in each model, based on either AC lesions scores or disease progression following time after induction. Interestingly, mineralised nodules were visible primarily in the medial compartment of both models, where AC degradation is known to occur, but spread to the lateral compartments in more severe joints. This could be linked to changes in the mechanical environment of the joint affecting the whole organ in severe cases. The reproducibility of the increases in mineralised tissue volume with $\mathrm{OA}$ in both models suggests that this method may be a strong predictor of disease severity and progression. We did not attempt to separate changes of each tissue within this joint space as identification of ligament and meniscus was not always clear, and may therefore result in interpretation errors. This new method could also be used as a noninvasive marker of disease progression in mice in vivo.

\section{Conclusions}

Our description of meniscal and ligament tissue modifications with the advancement of $\mathrm{OA}$ in two different mouse models suggests that these changes are an important hallmark of a disease. The reproducibility of these events and the possible functional implications in these innervated tissues, such as mechanical disturbances and pain, emphasises the need for further studies and for systematic reporting of these events in future in vivo studies. In addition, changes in joint space mineralised tissue volume measurements during OA development, suggest an important new method of following and quantifying disease progression using noninvasive $\mu \mathrm{CT}$ imaging techniques.

\section{Supplementary information}

Supplementary information accompanies this paper at https://doi.org/10. 1186/s13075-020-02261-5.

\section{Additional file 1}

\section{Abbreviations}

3D: 3-Dimensions; $A C$ : Articular cartilage; $A C L$ : Anterior cruciate ligament; BMP: Bone morphogenetic proteins; Col2: Collagen type II; DAB: 3,3'-
Diaminobenzidine; DMM: Destabilisation of medial meniscus; OA: Osteoarthritis; Sox9: SRY-box 9; TGFß: Transforming growth factor $\beta$; $\mu \mathrm{CT}$ : Micro-computed tomography

\section{Acknowledgements}

Not applicable.

\section{Authors' contributions}

Study concept and design: B.P., A.P.. Acquisition, analysis and interpretation of data: all authors. Statistical analysis: B. P, L.R. Drafting of the manuscript: all authors. Critical revision of the manuscript: all authors. The authors read and approved the final manuscript.

\section{Funding}

We are grateful to Arthritis Research UK (grants 18768, 19770, 20039, 20258, 20581), BBSRC BB/I014608/1, Wellcome Trust Equipment Grant, The MRCArthritis Research UK Centre for Integrated Research into Musculoskeletal Ageing (CIMA), and the Institute of Aging and Chronic Disease (University of Liverpool) for providing funding for this study.

\section{Availability of data and materials}

Data used in this manuscript can be accessed through email request to the corresponding author.

Ethics approval and consent to participate Not applicable.

\section{Consent for publication}

Not applicable.

\section{Competing interests}

We have no competing interests to declare.

\section{Author details}

${ }^{1}$ Institute of Lifecourse and Medical Sciences, University of Liverpool, 6 West Derby street, L7 8TX Liverpool, UK. ²Comparative Biomedical Sciences, The Royal Veterinary College, Royal College Street, London NW1 OTU, UK. ${ }^{3}$ Institute of Veterinary Science, Leahurst Campus, University of Liverpool, Chester High Rd, Neston CH64 7TE, UK.

Received: 6 November 2019 Accepted: 6 July 2020

Published online: 16 July 2020

\section{References}

1. Bobinac D, Spanjol J, Zoricic S, Maric I. Changes in articular cartilage and subchondral bone histomorphometry in osteoarthritic knee joints in humans. Bone. 2003:32(3):284-90.

2. McDevitt C, Gilbertson E, Muir H. An experimental model of osteoarthritis; early morphological and biochemical changes. J Bone Joint Surg Br. 1977 ; 59(1):24-35

3. Loeser RF, Goldring SR, Scanzello CR, Goldring MB. Osteoarthritis: a disease of the joint as an organ. Arthritis Rheum. 2012;64(6):1697-707.

4. Kamekura S, Hoshi K, Shimoaka T, Chung U, Chikuda H, Yamada T, Uchida M, Ogata N, Seichi A, Nakamura K, et al. Osteoarthritis development in nove experimental mouse models induced by knee joint instability. Osteoarthr Cartil. 2005;13(7):632-41.

5. Glasson SS, Blanchet TJ, Morris EA. The surgical destabilization of the medial meniscus (DMM) model of osteoarthritis in the 129/SvEv mouse. Osteoarthr Cartil. 2007;15(9):1061-9.

6. Pond MJ, Nuki G. Experimentally-induced osteoarthritis in the dog. Ann Rheum Dis. 1973;32(4):387-8.

7. Collins C, Evans RG, Ponsford F, Miller P, Elson CJ. Chondro-osseous metaplasia, bone density and patellar cartilage proteoglycan content in the osteoarthritis of STR/ORT mice. Osteoarthr Cartil. 1994;2(2):111-8.

8. Walton M. Degenerative joint disease in the mouse knee; histological observations. J Pathol. 1977;123(2):109-22.

9. Walton M. Degenerative joint disease in the mouse knee; radiological and morphological observations. J Pathol. 1977b;123(2):97-107.

10. Pest MA, Russell BA, Zhang YW, Jeong JW, Beier F. Disturbed cartilage and joint homeostasis resulting from a loss of mitogen-inducible gene 6 in a 
mouse model of joint dysfunction. Arthritis Rheumatol (Hoboken, NJ). 2014; 66(10):2816-27.

11. Xie J, Zhang D, Lin Y, Yuan Q, Zhou X. Anterior cruciate ligament transection-induced cellular and extracellular events in menisci: implications for osteoarthritis. Am J Sports Med. 2018;46(5):1185-98.

12. Hiyama K, Muneta T, Koga H, Sekiya I, Tsuji K. Meniscal regeneration after resection of the anterior half of the medial meniscus in mice. J Orthop Res. 2017;35(9):1958-65.

13. Messner K, Gao J. The menisci of the knee joint. Anatomical and functiona characteristics, and a rationale for clinical treatment. J Anat. 1998;193(Pt 2): 161-78.

14. Gamer $L W$, Xiang L, Rosen V. Formation and maturation of the murine meniscus. J Orthop Res. 2017;35(8):1683-9.

15. Frank CB. Ligament structure, physiology and function. J Musculoskelet Neuronal Interact. 2004;4(2):199-201.

16. Mienaltowski MJ, Birk DE. Mouse models in tendon and ligament research. Adv Exp Med Biol. 2014;802:201-30

17. Lohmander LS, Englund PM, Dahl LL, Roos EM. The long-term consequence of anterior cruciate ligament and meniscus injuries: osteoarthritis. Am J Sports Med. 2007;35(10):1756-69.

18. Neuman P, Englund M, Kostogiannis I, Friden T, Roos H, Dahlberg LE. Prevalence of tibiofemoral osteoarthritis 15 years after nonoperative treatment of anterior cruciate ligament injury: a prospective cohort study. Am J Sports Med. 2008;36(9):1717-25.

19. Englund M, Guermazi A, Roemer FW, Aliabadi P, Yang M, Lewis CE, Torner J, Nevitt MC, Sack B, Felson DT. Meniscal tear in knees without surgery and the development of radiographic osteoarthritis among middle-aged and elderly persons: the multicenter osteoarthritis study. Arthritis Rheum. 2009; 60(3):831-9.

20. Anderson-MacKenzie JM, Billingham ME, Bailey AJ. Collagen remodeling in the anterior cruciate ligament associated with developing spontaneous murine osteoarthritis. Biochem Biophys Res Commun. 1999;258(3):763-7.

21. Quasnichka HL, Anderson-MacKenzie JM, Bailey AJ. Subchondral bone and ligament changes precede cartilage degradation in guinea pig osteoarthritis. Biorheology. 2006:43(3-4):389-97.

22. Lorenz J, Grassel S. Experimental osteoarthritis models in mice. Methods Mole Biol (Clifton, NJ). 2014;1194:401-19.

23. Christiansen BA, Guilak F, Lockwood KA, Olson SA, Pitsillides AA, Sandell $\sqcup$, Silva MJ, van der Meulen MCH, Haudenschild DR. Non-invasive mouse models of post-traumatic osteoarthritis. Osteoarthr Cartil. 2015;23(10):1627-38.

24. Jay GE Jr, Sokoloff L. Natural history of degenerative joint disease in small laboratory animals. II. Epiphyseal maturation and osteoarthritis of the knee of mice of inbred strains. AMA Arch Pathol. 1956;62(2):129-35.

25. Walton M, Elves MW. Bone thickening in osteoarthrosis. Observations of an osteoarthrosis-prone strain of mouse. Acta Orthop Scand. 1979;50(5):501-6

26. Brewster M, Lewis EJ, Wilson KL, Greenham AK, Bottomley KM. Ro 32-3555, an orally active collagenase selective inhibitor, prevents structural damage in the STR/ORT mouse model of osteoarthritis. Arthritis Rheum. 1998;41(9): 1639-44.

27. Blaney Davidson EN, Vitters EL, van der Kraan PM, van den Berg WB. Expression of transforming growth factor-beta (TGFbeta) and the TGFbeta signalling molecule SMAD-2P in spontaneous and instability-induced osteoarthritis: role in cartilage degradation, chondrogenesis and osteophyte formation. Ann Rheum Dis. 2006;65(11):1414-21.

28. Poulet B, Ulici V, Stone TC, Pead M, Gburcik V, Constantinou E, Palmer DB, Beier F, Timmons JA, Pitsillides AA. Time-series transcriptional profiling yields new perspectives on susceptibility to osteoarthritis. Arthritis Rheum. 2012. 64(10):3256-66.

29. Poulet B, Westerhof TA, Hamilton RW, Shefelbine SJ, Pitsillides AA. Spontaneous osteoarthritis in Str/ort mice is unlikely due to greater vulnerability to mechanical trauma. Osteoarthr Cartil. 2013;21(5):756-63.

30. Loeser RF, Olex A, McNulty MA, Carlson CS, Callahan M, Ferguson C, Chou J, Leng X, Fetrow JS: Microarray analysis reveals age-related differences in gene expression during the development of osteoarthritis in mice. Arthritis Rheum. 2012;64(3):705-17.

31. McNulty MA, Loeser RF, Davey C, Callahan MF, Ferguson CM, Carlson CS Histopathology of naturally occurring and surgically induced osteoarthritis in mice. Osteoarthr Cartil. 2012;20(8):949-56.

32. Glasson SS, Chambers MG, Van Den Berg WB, Little CB. The OARSI histopathology initiative - recommendations for histological assessments of osteoarthritis in the mouse. Osteoarthr Cartil. 2010;18(Suppl 3):S17-23.
33. Mason RM, Chambers MG, Flannelly J, Gaffen JD, Dudhia J, Bayliss MT. The STR/ort mouse and its use as a model of osteoarthritis. Osteoarthr Cartil. 2001;9(2):85-91.

34. Gardiner MD, Vincent TL, Driscoll C, Burleigh A, Bou-Gharios G, Saklatvala J, Nagase $\mathrm{H}$, Chanalaris A. Transcriptional analysis of micro-dissected articular cartilage in post-traumatic murine osteoarthritis. Osteoarthr Cartil. 2015; 23(4):616-28.

35. Little CB, Zaki S. What constitutes an "animal model of osteoarthritis"--the need for consensus? Osteoarthr Cartil. 2012;20(4):261-7.

36. Kwok J, Onuma H, Olmer M, Lotz MK, Grogan SP, D'Lima DD. Histopathological analyses of murine menisci: implications for joint aging and osteoarthritis. Osteoarthr Cartil. 2016;24(4):709-18.

37. Cooper RR, Misol S. Tendon and ligament insertion. A light and electron microscopic study. J Bone Joint Surg Am. 1970;52(1):1-20.

38. Hasegawa A, Otsuki S, Pauli C, Miyaki S, Patil S, Steklov N, Kinoshita M, Koziol J, D'Lima DD, Lotz MK. Anterior cruciate ligament changes in the human knee joint in aging and osteoarthritis. Arthritis \& Rheumatism. 2012;64(3): 696-704.

39. Englund M, Felson DT, Guermazi A, Roemer FW, Wang K, Crema MD, Lynch JA, Sharma L, Segal NA, Lewis CE, et al. Risk factors for medial meniscal pathology on knee MRI in older US adults: a multicentre prospective cohort study. Ann Rheum Dis. 2011;70(10):1733-9.

40. Raustol OA, Poelstra KA, Chhabra A, Diduch DR. The meniscal ossicle revisited: etiology and an arthroscopic technique for treatment. Arthroscopy. 2006;22(6):687 e681-683.

41. Sun Y, Mauerhan DR, Honeycutt PR, Kneisl JS, Norton HJ, Zinchenko N, Hanley EN Jr, Gruber HE. Calcium deposition in osteoarthritic meniscus and meniscal cell culture. Arthritis Res Ther. 2010;12(2):R56.

42. Pauli C, Grogan SP, Patil S, Otsuki S, Hasegawa A, Koziol J, Lotz MK, D'Lima DD. Macroscopic and histopathologic analysis of human knee menisci in aging and osteoarthritis. Osteoarthr Cartil. 2011;19(9):1132-41.

43. Thomsen JS, Straarup TS, Danielsen CC, Oxlund H, Bruel A. Relationship between articular cartilage damage and subchondral bone properties and meniscal ossification in the Dunkin Hartley guinea pig model of osteoarthritis. Scand J Rheumatol. 2011;40(5):391-9.

44. Cheung HS, Sallis JD, Demadis KD, Wierzbicki A. Phosphocitrate blocks calcification-induced articular joint degeneration in a guinea pig model. Arthritis Rheum. 2006;54(8):2452-61.

45. Jorgensen B, Jensen HE. Periarticular ossification at the elbow joint and meniscal ossification in the stifle joint of pigs--occurrence, pathomorphology, breed differences and correlations with osteochondrosis, leg weakness and production parameters. J Vet Med A Physiol Pathol Clin Med. 2002;49(7):353-7.

46. Weber NA. Apparent primary ossification of the menisci in a dog. J Am Vet Med Assoc. 1998;212(12):1892-4.

47. Ernest TL, Kondrashov PE. The role of excessive body weight and meniscal instability in the progression of osteoarthritis in a rat model. Knee. 2018; 25(6):1151-6.

48. Sugita D, Yayama T, Uchida K, Kokubo Y, Nakajima H, Yamagishi A, Takeura $\mathrm{N}$, Baba H. Indian hedgehog signaling promotes chondrocyte differentiation in enchondral ossification in human cervical ossification of the posterior longitudinal ligament. Spine. 2013;38(22):E1388-96.

49. Uchida K, Yayama T, Cai HX, Nakajima H, Sugita D, Guerrero AR, Kobayashi S, Yoshida A, Chen KB, Baba H. Ossification process involving the human thoracic ligamentum flavum: role of transcription factors. Arthritis Res Ther. 2011;13(5):R144.

50. Levy YD, Hasegawa A, Patil S, Koziol JA, Lotz MK, D'Lima DD. Histopathological changes in the human posterior cruciate ligament during aging and osteoarthritis: correlations with anterior cruciate ligament and cartilage changes. Ann Rheum Dis. 2013;72(2):271-7.

51. Zhu M, Chen M, Zuscik M, Wu Q, Wang YJ, Rosier RN, O'Keefe RJ, Chen D. Inhibition of beta-catenin signaling in articular chondrocytes results in articular cartilage destruction. Arthritis Rheum. 2008;58(7):2053-64

52. Zhu M, Tang D, Wu Q, Hao S, Chen M, Xie C, Rosier RN, O'Keefe RJ, Zuscik $M$, Chen D. Activation of beta-catenin signaling in articular chondrocytes leads to osteoarthritis-like phenotype in adult beta-catenin conditional activation mice. J Bone Miner Res. 2009;24(1):12-21.

53. Wei F, Zhou J, Wei X, Zhang J, Fleming BC, Terek R, Pei M, Chen Q, Liu T, Wei L. Activation of Indian hedgehog promotes chondrocyte hypertrophy and upregulation of MMP-13 in human osteoarthritic cartilage. Osteoarthr Cartil. 2012;20(7):755-63. 
54. Zhou J, Chen Q, Lanske B, Fleming BC, Terek R, Wei X, Zhang G, Wang S, Li $\mathrm{K}$, Wei L. Disrupting the Indian hedgehog signaling pathway in vivo attenuates surgically induced osteoarthritis progression in Col2a1-CreERT2; Ihhfl/fl mice. Arthritis Res Ther. 2014;16(1):R11.

55. Zhou J, Wei X, Wei L. Indian hedgehog, a critical modulator in osteoarthritis, could be a potential therapeutic target for attenuating cartilage degeneration disease. Connect Tissue Res. 2014;55(4):257-61.

56. Park JO, Lee BH, Kang YM, Kim TH, Yoon JY, Kim H, Kwon UH, Lee KI, Lee $\mathrm{HM}$, Moon SH. Inflammatory cytokines induce fibrosis and ossification of human ligamentum flavum cells. J Spinal Disord Tech. 2013;26(1):E6-12.

57. Kong Q, Ma X, Li F, Guo Z, Qi Q, Li W, Yuan H, Wang Z, Chen Z. COL6A1 polymorphisms associated with ossification of the ligamentum flavum and ossification of the posterior longitudinal ligament. Spine. 2007:32(25):2834-8.

58. Liu Y, Zhao Y, Chen Y, Shi G, Yuan W. RUNX2 polymorphisms associated with OPLL and OLF in the Han population. Clin Orthop Relat Res. 2010; 468(12):3333-41.

59. Alexopoulos LG, Youn I, Bonaldo P, Guilak F. Developmental and osteoarthritic changes in Col6a1-knockout mice: biomechanics of type $\mathrm{VI}$ collagen in the cartilage pericellular matrix. Arthritis Rheum. 2009; 60(3):771-9.

60. Kamekura S, Kawasaki Y, Hoshi K, Shimoaka T, Chikuda H, Maruyama Z Komori T, Sato S, Takeda S, Karsenty G, et al. Contribution of runt-related transcription factor 2 to the pathogenesis of osteoarthritis in mice after induction of knee joint instability. Arthritis Rheum. 2006;54(8):2462-70.

61. Hou XF, Fan DW, Sun CG, Chen ZQ. Recombinant human bone morphogenetic protein-2-induced ossification of the ligamentum flavum in rats and the associated global modification of histone H3. J Neurosurg Spine. 2014;21 (3):334-41.

62. Hayashi $K$, Ishidou $Y$, Yonemori $K$, Nagamine $T$, Origuchi $N$, Maeda $S$, Imamura T, Kato M, Yoshida H, Sampath TK, et al. Expression and localization of bone morphogenetic proteins (BMPs) and BMP receptors in ossification of the ligamentum flavum. Bone. 1997;21(1):23-30.

63. Cai HX, Yayama T, Uchida K, Nakajima H, Sugita D, Guerrero AR, Yoshida A, Baba H. Cyclic tensile strain facilitates the ossification of ligamentum flavum through beta-catenin signaling pathway: in vitro analysis. Spine. 2012;37(11): E639-46.

64. Tang M, Peng Z, Mai Z, Chen L, Mao Q, Chen Z, Chen Q, Liu L, Wang Y, Ai $H$. Fluid shear stress stimulates osteogenic differentiation of human periodontal ligament cells via the extracellular signal-regulated kinase 1/2 and p38 mitogen-activated protein kinase signaling pathways. J Periodontol. 2014;85(12):1806-13.

65. Tang N, Zhao Z, Zhang L, Yu Q, Li J, Xu Z, Li X. Up-regulated osteogenic transcription factors during early response of human periodontal ligament stem cells to cyclic tensile strain. Archives Med Sci. 2012;8(3):422-30.

66. Poulet B, Hamilton RW, Shefelbine S, Pitsillides AA. Characterizing a novel and adjustable noninvasive murine joint loading model. Arthritis Rheum. 2011;63(1):137-47.

67. Kim HA, Kim I, Song YW, Kim DH, Niu J, Guermazi A, Crema MD, Hunter DJ, Zhang Y. The association between meniscal and cruciate ligament damage and knee pain in community residents. Osteoarthr Cartil. 2011;19(12):1422-8.

68. Ashraf S, Walsh DA. Angiogenesis in osteoarthritis. Curr Opin Rheumatol. 2008;20(5):573-80.

69. Little CB, Barai A, Burkhardt D, Smith SM, Fosang AJ, Werb Z, Shah M, Thompson EW. Matrix metalloproteinase 13-deficient mice are resistant to osteoarthritic cartilage erosion but not chondrocyte hypertrophy or osteophyte development. Arthritis Rheum. 2009;60(12):3723-33.

\section{Publisher's Note}

Springer Nature remains neutral with regard to jurisdictional claims in published maps and institutional affiliations.

Ready to submit your research? Choose BMC and benefit from:

- fast, convenient online submission

- thorough peer review by experienced researchers in your field

- rapid publication on acceptance

- support for research data, including large and complex data types

- gold Open Access which fosters wider collaboration and increased citations

- maximum visibility for your research: over $100 \mathrm{M}$ website views per year

At BMC, research is always in progress.

Learn more biomedcentral.com/submissions 